\title{
Novel Stylus Method FOR Measuring PAPERS TOPOGRAPHY
}

\author{
MOŽINA, K.
}

Abstract: Papers topography is of great importance primarily to the printability. Since papers rarely end as a blank sheet, it is therefore significant how will the print-outs appear. Paper topography was evaluated with standard stylus technique, i.e. profilometer TR200, novel contact stylus method, i.e. "Instron" and non-contact method, i.e. 3D laser scanning microscopy. Because of the high processing velocities, the non-contact techniques are industries preferable way of performing standard measurements. In case of a paper production, paper mills have one mayor problem with on- or off-line optical measuring units. Since the nature of the paper production is overall mixture of water, calcium carbonate, latex etc., particles, i.e. fuzz, that is present in the surrounding atmosphere along the paper machine, therefore surface of optics on measuring on-line unit tends to get dirty and capturing accurate data is due to the working environment aggravated. Consequently, the novel stylus method has been developed for measuring paper roughness. In the basic, the novel method is an upgrade of standard technique used on dynamometers for measuring friction force. Afterwards the friction force is transformed into the parameters, normally used when presenting surface roughness, i.e. $R_{a}, R_{q}, R_{p}$ and $R_{v}$.

Key words: paper, roughness, stylus, Instron, TR200, 3D laser scanning
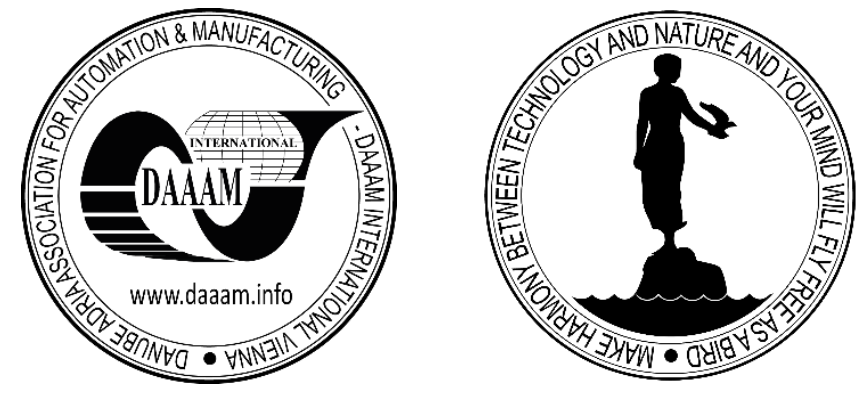

Authors' data: doc. dr. Možina, K[lemen]; University of Ljubljana, Faculty of Natural Sciences and Engineering, Department of Textiles, Graphic Arts and Design, Snežniska 5, 1000 Ljubljana, Slovenia, klemen.mozina@ntf.uni-lj.si

This Publication has to be referred as: Mozina, K[lemen] (2018). Novel Stylus Method for Measuring Papers Topography, Chapter 20 in DAAAM International Scientific Book 2018, pp.227-238, B. Katalinic (Ed.), Published by DAAAM International, ISBN 978-3-902734-19-8, ISSN 1726-9687, Vienna, Austria

DOI: $10.2507 /$ daaam.scibook.2018.20 


\section{Introduction}

Surface topography is of a great importance to many industrial metrology, i.e. contact mechanics, fluid flow, optics, electronic, bio-engineering and paper production as well $(1=$ Persson, 2006, NOVO = Maculotti et al, 2018). Currently are available diverse measuring methods for determining the common standard parameters, $R_{a}, R_{q}$, $R_{p}, R_{v}$ and are generally divided into two categories according to whether or not the measuring probe touches the surface of the test piece, i.e. contact and non-contact techniques ( 2 = Asakura, 1978; 3 = Asl-Kindi \& Shirinzadeh, 2009). Papers topography measured with profilometric method has been in the past most commonly used standard technique. But the profilometric method has two major drawbacks: first, it often damages the papers surface, which is due to the trace of the narrow diamond stylus and second, it measures only the average surface peak and valley, independently to the correlation of the length of the path or to the average gradient of papers topography.

Overall the correlation length and average gradient can be calculated after the measurement, if the electronic signal from the profilometer is obtained $(4=$ Ohtsubo et al., 1975). Because of the two mentioned drawbacks, substantial investigations on non-contact, i.e. optical methods have been proposed. Kiran et al. $(5=$ Kiran et al., 1998) used a measure unit called texture unit, where the surface topography was calculated from the grey scale of the captured image. The proposed technique is limited to a small surface area and therefore it has not been used in engineering purposes. Tasan et al. ( 6 = Tasan et al., 2005) proposed a wear measuring technique which is based on the local surface heights of a larger number of captured images and in the end overlaid and evaluated upon the average values of peaks and valleys. Al-Kindi et al. ( $7=\mathrm{Al}-$ Kindi et al., 1992) combined spacing and amplitude parameters obtained from the grey level profiles to calculate the surface roughness. Overall, the tree mentioned technique did not meet the expectations for measuring the surface topography, because they were not robust methodologies that could be adopted for computer vision-based roughness assessment. Several other optical methods and applications to measure the surface topography have been developed and implemented in the laboratories and on-line measuring units, among which are widely used interferometry ( $8=$ Wyant et al., 1980), light scattering ( $9=$ Bennett, 1992), focus (10 = Mitsui, 1986), airborne ultrasound (11 $=$ Stor-Pellinen \& Luukkala, 1995) and as already mentioned, speckle method (2= Asakura, 1978; 12 = Persson, 1999).

Paper with its complex structure of cellulose fibers distributed at multiple levels and surrounded predominantly with filler, i.e. GCC, creates a network that can be wide from few nanometers and it can be as big as few centimeters. The hierarchical ordering is formed during the paper production on the paper machine, where the specific interactions within the papers network can be turned by modifying pulp composition and crucial parameters on paper machine, i.e. the speed of a stock inlet and wire. Because the individual fibre and network properties do affect the final paper performance and may often be floculated or anisotropically distributed the end result is reflected in physical-mechanical characteristics and surface topography $(13=$ Samyn et al., 2011; 14 = Alava \& Niskanen, 2006; 15 = Kortschot, 1997; 16 = Baghello \& 
Eklund, 1997; 17 = Koran \& Silvy, 1986). Complexity of anisotropy is not only presented as the bulk in paper, it also manifests as the surface disparity and it determines end properties, i.e. visual appearance (colour, gloss, flatness), printability (capillary rise, ink absorption and drying), processability (friction) and barrier resistance (water absorption, gas and grease penetration). Therefore, monitoring papers topography is of great importance for quality control of production line and above all it provides insight on how to improve surface properties ( $18=$ Kettle et al., 2010; $19=$ Johansson et al., 1998; 20 = Dury Bruna et al., 2006; $21=$ Despond et al., 2005; $22=$ Reis \& Saraiva, 2006; 23 = Alam et al., 2012).

Surface topography affects papers optical properties, i.e. gloss and ink absorption. Smoothness is closely related to the uniform transfer of printing ink; therefore, paper surface is an important physical quality of evaluating papers convex or concave deviation. Paper topography can also be closely related to the properties of individual pigment particles and fibre disposal in the paper and it is also related to the shape, variety, position and fines of the web network. Overall the paper smoothness is the result of paper formation ( $24=$ Aguilar et al., 2009; $25=$ Zhou et al., 2012; $26=$ Juuti, 2007). Representatives of direct off-line analysis methods for measuring paper topography are currently Bendtsen, PPS, Buick, while non-standardized, on-line alternative for indirect measuring techniques are a combination of optical and ultrasonic methods.

Optical methods are divided into two categories, i.e. the ones that determine the roughness/smoothness by means of Fourier transformation analyses $(24=$ Aguilar et al., 2009), and those based on 3D visualization determined on optical coherence tomography $(27$ = Alarousu et al., 2005). It should be pointed that listed optical methods are very expensive, i.e. in terms of economical and computational terms. On the other hand, the ultrasonic methods consist of measuring ultrasonic impedance and mass specific ultrasonic attenuation provided by paper surface which can be correlated to surface roughness $(28=$ Brodeur et al., 1993). Most common off-line analysis technique is stylus tracking method, beside the microscopy, pneumatic and light scattering. When acoustic and stylus techniques are compared, the acoustic has the higher scanning speed and does not provide the actual profile, on the other hand, the stylus contact method has a slower scanning speed, where the actual profile can be obtained (29 = Hiziroglu, 1996; 30 = Tammineni \& Reddy Yedula, 2014).

Therefore, the stylus technique is widely used when the surface roughness is discussed and that is due to its accuracy, practicality and most important, repeatability. Parameters such as the stylus tip radius, the friction and the cut-off length of the profile, i.e. a filtering parameter that separates unfiltered actual profile into waviness and roughness profiles, have a great effect on the accuracy of the results (29 Hiziroglu, 1996; 31 = Ostman, 1983; 32 = Peter \& Cumming, 1970).

\section{Experimental part}

\subsection{Materials}

Paper samples, taken from different production steps, i.e. base paper $\left(\mathrm{B}=57 \mathrm{~g} / \mathrm{m}^{2}\right)$, coated $\left(\mathrm{C}=78 \mathrm{~g} / \mathrm{m}^{2}\right)$ and calandered $\left(\mathrm{CA}=78 \mathrm{~g} / \mathrm{m}^{2}\right)$ were evaluated with tree 
measuring techniques. On each paper sheet, 5 measurements were performed in machine direction (MD) and cross direction (CD), but only the results for MD are demonstrated in the paper. Studied papers are produced for purposes of flex packaging (label paper), for which the surface smoothness is of great importance, i.e. predominantly printability.

\subsection{Measuring techniques}

\subsubsection{Stylus technique}

\subsubsection{Hand held roughness tester TR200}

Macro roughness of papers was measured with hand-held roughness tester TR200, Portable Testers ${ }^{\mathrm{TM}}$. A stylus is tracked across the papers surface, where at the regular interval, the amplitude of the fall and raise is recorded. The light weighted load is applied on the relatively large diamond stylus tip, 15,4 $\mu \mathrm{m}$ (Fig. 1), which is designed not to distort the specimen surface during the measurement.

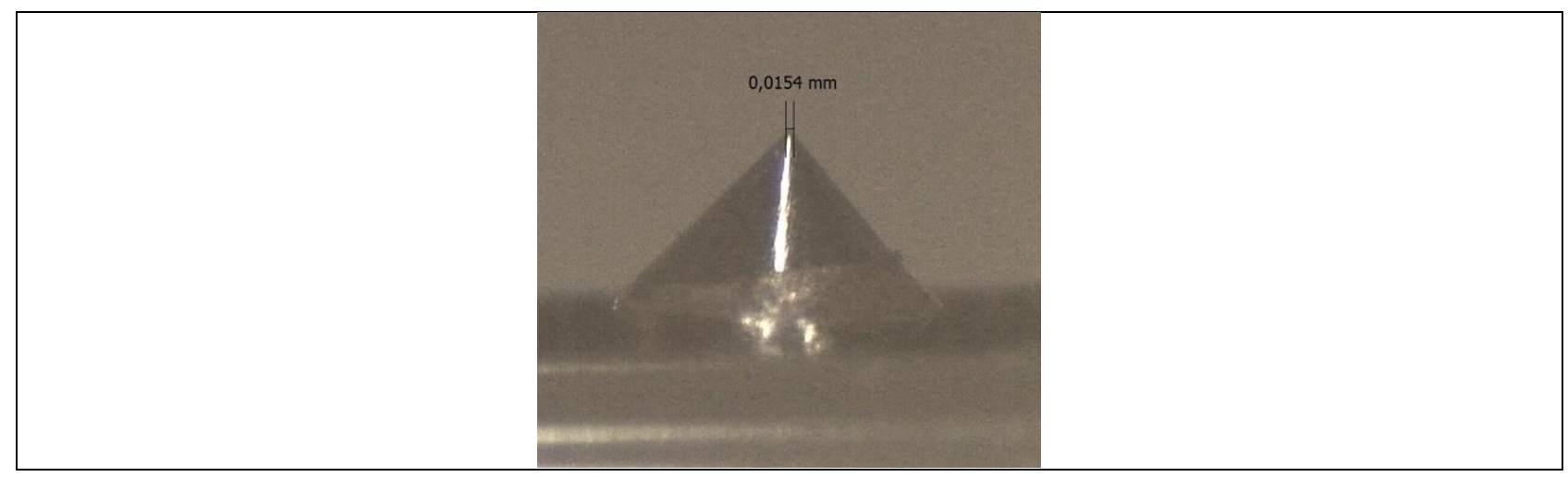

Fig. 1. Diamond stylus tip on the TR200.

According to ISO 4287 standard (33 = ISO 4287, 1997), cut-off length was selected to be 2,5 times the peak-to-peak spacing of the profile roughness. Therefore at least two minimums of two peaks and valleys can be covered within each cut-off length. If selecting the wrong cut-off, it may result in an inaccurate calculated roughness parameter, i.e. $R_{a}, R_{z}$ and $R_{\max }$.

Considering mentioned, the overall profile is leveled and that the height, $h_{i}$, is measured at $N$ locations along the profile length, $L$, then the surface roughness is numerically calculated as:

$$
\mathrm{R}_{\mathrm{a}}=\frac{1}{\mathrm{~N}} \sum_{\mathrm{i}=1}^{\mathrm{N}}\left|\mathrm{h}_{\mathrm{i}}\right|
$$

Where the root-mean-square deviation of profile is calculated as:

$$
\mathrm{R}_{\mathrm{q}}=\left(\frac{1}{\mathrm{~N}} \sum_{\mathrm{i}=1}^{\mathrm{N}} \mathrm{h}_{\mathrm{i}}^{2}\right)^{\frac{1}{2}}
$$




\subsubsection{2 »Instron « method}

Developing novel stylus method originates from the fact that standardised method, i.e. TR200, has the limited measuring length $(0,25,0,80$, and $2,50 \mathrm{~mm})$. Paper is a heterogeneous material. Therefore, to be able to measure over the set-up length, i.e. above $2,50 \mathrm{~mm}$, was the primary cause in developing new contact measuring technique. Since the profilometers, i.e. TR200 are constructed to measure friction of the stylus crossing over the media surface and record the friction force, the idea was, can it be done differently. It can be done, but some modifications of existing measuring equipment, dynamometer Instron 5567, were necessary. First the method had to be modified to the profilometer in a way, that the special metal stylus (Fig. 2), had a tip of the stylus size as it is at TR200.

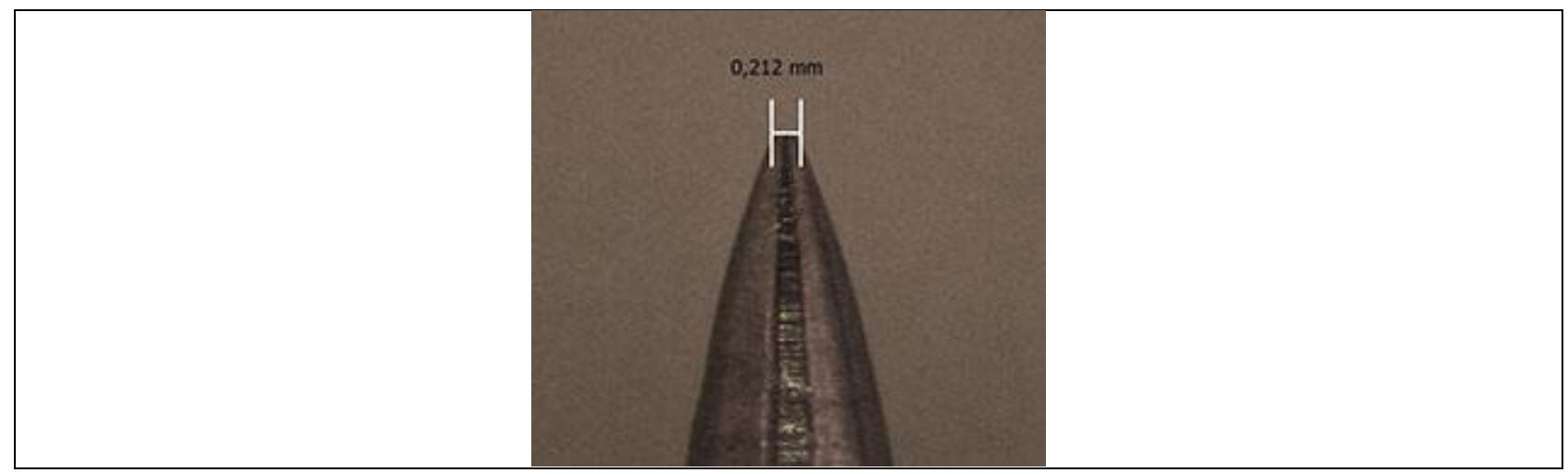

Fig. 2. Instron stylus tip.

Stylus mounted on a wheel carrier (Fig. 3), is moving along the paper surface without acceleration. The cart was connected via the pulley to the dynamometer with the thin string, which was unexpandable and had neglected mass. Therefore, due to the low mass of the cart, the »noise « that would appear if the mass of the wheel carrier and the string would be significant higher, can be ignored. Also, the wheels on the cart do not cause and friction with the surface, i.e. spinning is sleek. Friction force is only induced by the contact between the stylus and the paper surface.

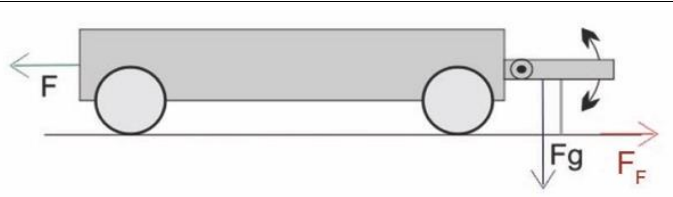

Fig. 3. The structure of the wheel carrier.

On account of uniform movement of the cart, the $1^{\text {st }}$ Newtonian law can be introduced in to the salving of the problem. It can be easily concluded that the total sum of the forces influencing on the moving or idle wheel carrier is equal to 0, i.e. $F=F_{f}$ and $F_{g}=F_{N}$, where is $F_{f}-$ friction force, $F_{g}-$ gravity force and $F_{N}-$ force to the surface.

On the basis of the stylus kinetics, the height difference, alteration in path and speed (Fig. 4) the height distinction, $\Delta h$, (Eq. 3): 


$$
\Delta \mathrm{h}=\mathrm{h}_{2}-\mathrm{h}_{1}=\mathrm{h}_{\mathrm{B}}-\mathrm{h}_{\mathrm{A}}=\mathrm{h}_{\mathrm{B}}
$$

and the path discrepancy, $\Delta s$, can be calculated, (Eq. 4).

$$
\Delta \mathrm{s}=\mathrm{s}_{2}-\mathrm{s}_{1}=\mathrm{s}_{\mathrm{B}}-\mathrm{s}_{\mathrm{A}}
$$

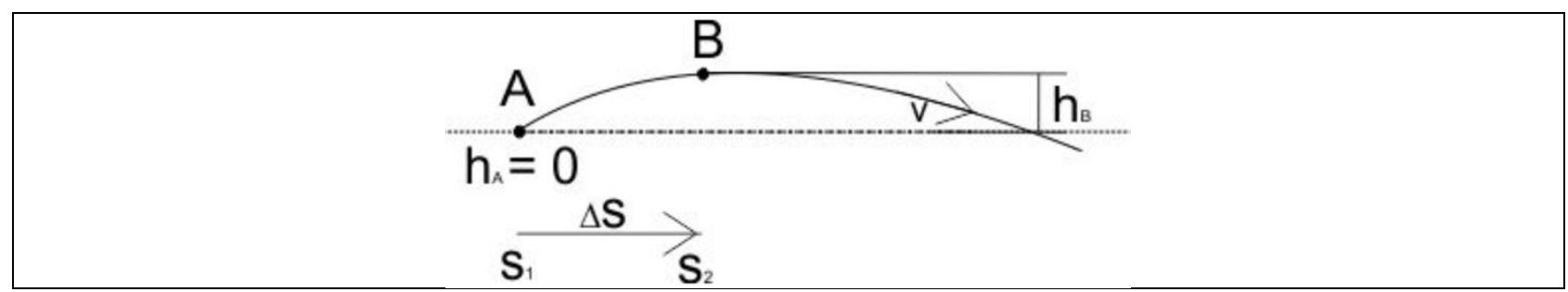

Fig. 4. Stylus kinetics.

Velocity, $v$, is held constant over the entire path, i.e. 5, 10, 20, $30 \mathrm{~cm}$. Energy variation, caused by the stylus on the transition from point $\mathrm{A}$ to $\mathrm{B}$ is equal to the work caused by the friction force.

$$
\Delta \mathrm{W}=\mathrm{A}_{\mathrm{F}}
$$

When measuring surface topography, the height change, $\Delta h$, is of the primary interest. Therefore, when taking everything into consideration, the end equation, from which the noted $\mathrm{R}_{\mathrm{a}}$ can be derived, can be written as:

$$
\mathrm{h}_{\mathrm{i}}=\mu_{\mathrm{i}} \mathrm{s}_{\mathrm{i}}-\frac{\mathrm{v}^{2}}{2 \mathrm{~g}}
$$

Equation 6 explains the transformation from the novel »Instron« method to the profilometer TR200 measured standard values of average roughness, $R_{a}$, as written in Eq. 1. The set-up speed at Instron dynamometer was $60 \mathrm{~mm} / \mathrm{min}$, for the length of $30 \mathrm{~mm}$.

\subsubsection{D laser scanning microscope technique Keyence VK-X250}

The 3D laser scanning microscope is as the name suggests mainly used for 3D surface analysis and characterization, unlike conventional optical microscopes. By incorporating two light sources, i.e. a white light for gathering color and a laser source for scanning the surface of an object and collecting detailed height information. The paper surface is scanned with a microscope, while the laser scan in all three dimensions, i.e. XYZ, to collect the data throughout the entire specified range. The output is a highresolution, large depth-of-field, color image with nanometer-level height resolution for accurate profile and roughness measurements. Specimens were scanned with standard objective lens, $50 \times$, brightness, 7200 and optical zoom, $1 \times$, on wired side of the paper, i.e. coated side of the paper. 


\section{Results and discussion}

Results of the surface topography values of studied label papers are presented in Tab. 1 .

\begin{tabular}{|c|c|c|c|c|c|c|}
\hline \multirow[b]{2}{*}{ Specimen } & \multirow[b]{2}{*}{$\rho\left[\mathrm{g} / \mathrm{cm}^{3}\right]$} & \multirow[b]{2}{*}{ Instrument } & \multicolumn{4}{|c|}{$\mathrm{R}[\mu \mathrm{m}]$} \\
\hline & & & $\mathrm{R}_{\mathrm{a}}$ & $\mathrm{R}_{\mathrm{q}}$ & $\mathrm{R}_{\mathrm{p}}$ & $\mathrm{R}_{\mathrm{V}}$ \\
\hline \multirow{3}{*}{ B } & \multirow{3}{*}{0,76} & TR200 & 3,784 & 4,701 & 10,786 & 13,758 \\
\hline & & VK-X250 & 1,617 & 2,021 & 3,782 & 5,044 \\
\hline & & Instron & 1,175 & 1,527 & 4,265 & 6,622 \\
\hline \multirow{3}{*}{$\mathrm{C}$} & \multirow{3}{*}{0,97} & TR200 & 1,253 & 1,557 & 3,139 & 4,319 \\
\hline & & VK-X250 & 0,691 & 0,847 & 1,801 & 2,101 \\
\hline & & Instron & 0,428 & 0,572 & 1,380 & 3,125 \\
\hline \multirow{3}{*}{ CA } & \multirow{3}{*}{1,17} & TR200 & 0,640 & 0,838 & 1,792 & 2,666 \\
\hline & & VK-X250 & 0,355 & 0,459 & 0,933 & 1,232 \\
\hline & & Instron & 0,423 & 0,587 & 2,176 & 2,595 \\
\hline
\end{tabular}

Tab. 1. Surface topography of all three measuring techniques and papers.

In general, the lowest values are measured with the Instron method. In average, over the studied paper samples (base (B), coated (C) and calandered (CA)), the $\mathrm{R}_{\mathrm{a}}$ is $0,675 \mu \mathrm{m}$, while the highest values are measured with the standard profilometer TR200, i.e. $1,892 \mu \mathrm{m}$ or $64,3 \%$ higher than the Instron method. Therefore, we can see from Table 1 that the novel contact stylus method is in closer relation to the 3D laser scanning method than it is to the standard stylus technique. If we compare the difference in measured, i.e. average roughness, $R_{a}$, the clear interception between the $3 D$ scanning microscope and the Instron method can be observed (Tab. 2).

\begin{tabular}{|c|c|c|c|}
\hline \multirow[b]{2}{*}{ Specimen } & \multirow[b]{2}{*}{ Method } & \multicolumn{2}{|c|}{ Discrepancy } \\
\hline & & {$[\mu \mathrm{m}]$} & {$[\%]$} \\
\hline \multirow{3}{*}{ B } & $\begin{array}{l}\text { TR200 } \\
\text { VK-250 }\end{array}$ & 2,167 & 134,0 \\
\hline & $\begin{array}{l}\text { TR200 } \\
\text { Instron }\end{array}$ & 2,609 & 222,0 \\
\hline & $\begin{array}{l}\text { VK-250 } \\
\text { Instron }\end{array}$ & 0,442 & 37,6 \\
\hline \multirow{3}{*}{$\mathrm{C}$} & $\begin{array}{l}\text { TR200 } \\
\text { VK-250 }\end{array}$ & 0,562 & 81,3 \\
\hline & $\begin{array}{l}\text { TR200 } \\
\text { Instron }\end{array}$ & 0,825 & 192,8 \\
\hline & $\begin{array}{l}\text { VK-250 } \\
\text { Instron }\end{array}$ & 0,263 & 61,5 \\
\hline \multirow{3}{*}{$\mathrm{CA}$} & $\begin{array}{l}\text { TR200 } \\
\text { VK-250 }\end{array}$ & 0,285 & 80,3 \\
\hline & $\begin{array}{l}\text { TR200 } \\
\text { Instron }\end{array}$ & 0,217 & 51,3 \\
\hline & $\begin{array}{l}\text { VK-250 } \\
\text { Instron }\end{array}$ & 0,068 & 19,2 \\
\hline
\end{tabular}

Tab. 2. Differences among the measurement techniques. 
The more the paper surface is treated (coated, calandered) the lower are discrepancies among the techniques, ranging from over $200 \%$ to a drop to 80 or even $50 \%$. When comparing the profiles presented in Fig. 5-7, it can be noticed the great deviation in papers topography measured with different techniques on the same surface. Although novel stylus method is based on the same physical foundations as profilometer, i.e. recording vertical movement, it has more resemblance to the $3 \mathrm{D}$ laser scanned measurements as it has with the contact profilometer.
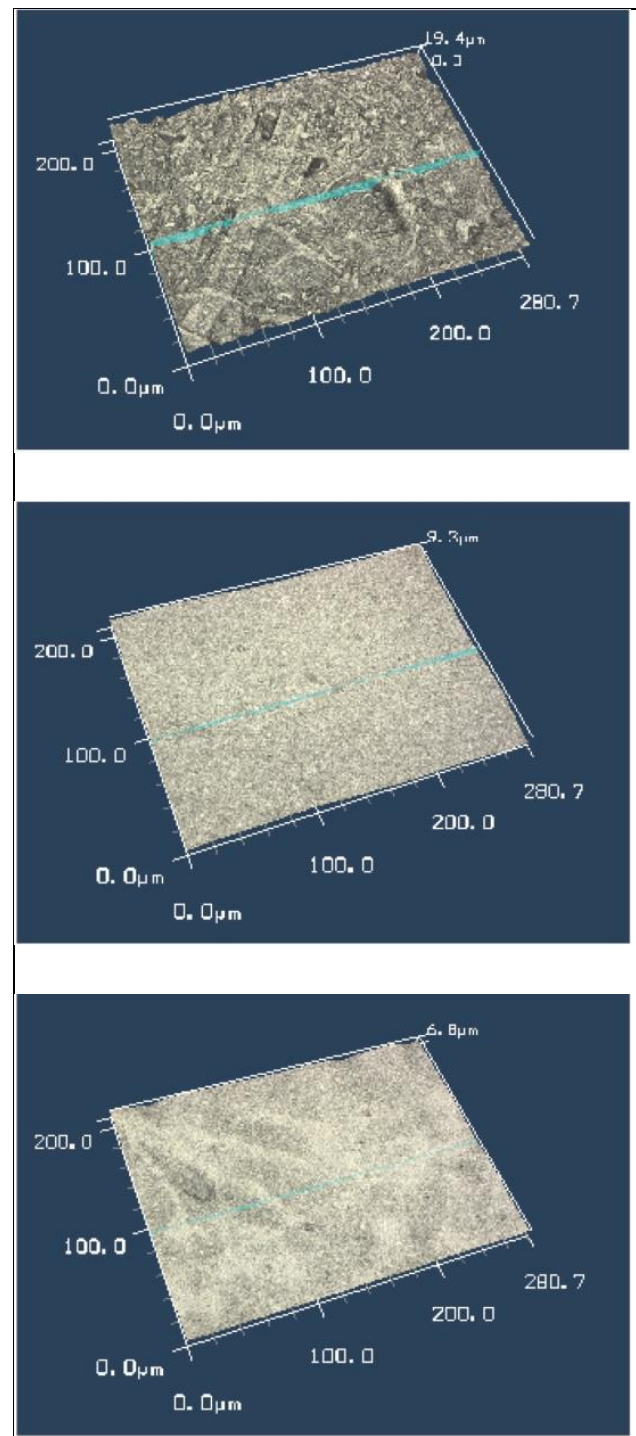

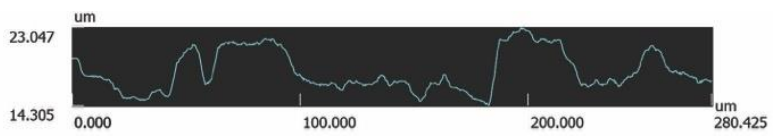

base

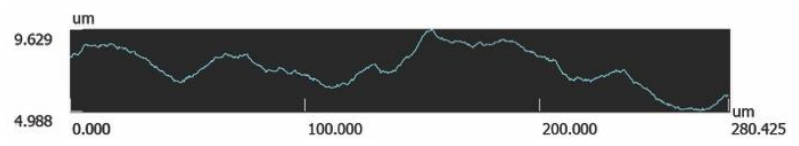

coated

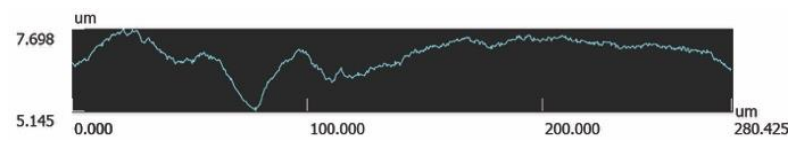

Fig. 5. Profile of surface roughness - TR200.

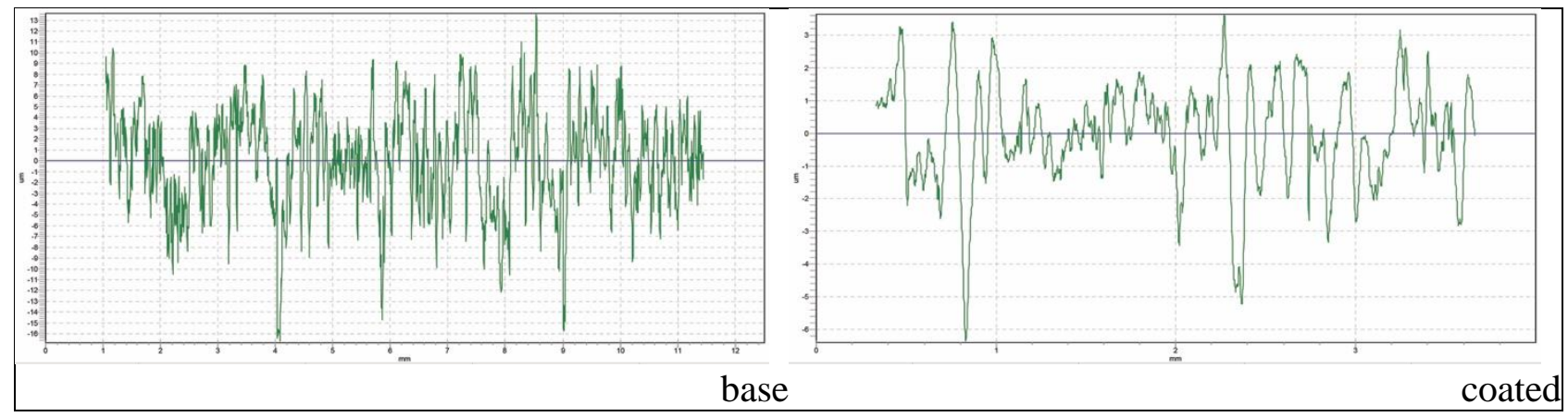




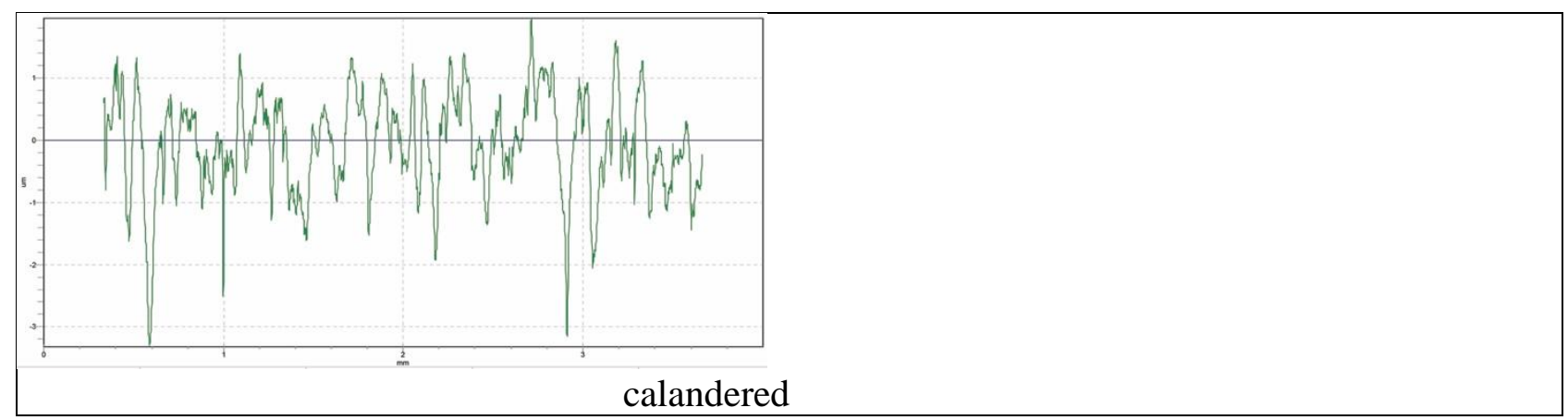

Fig. 6. Profile of surface roughness - Keyence VK-X250.

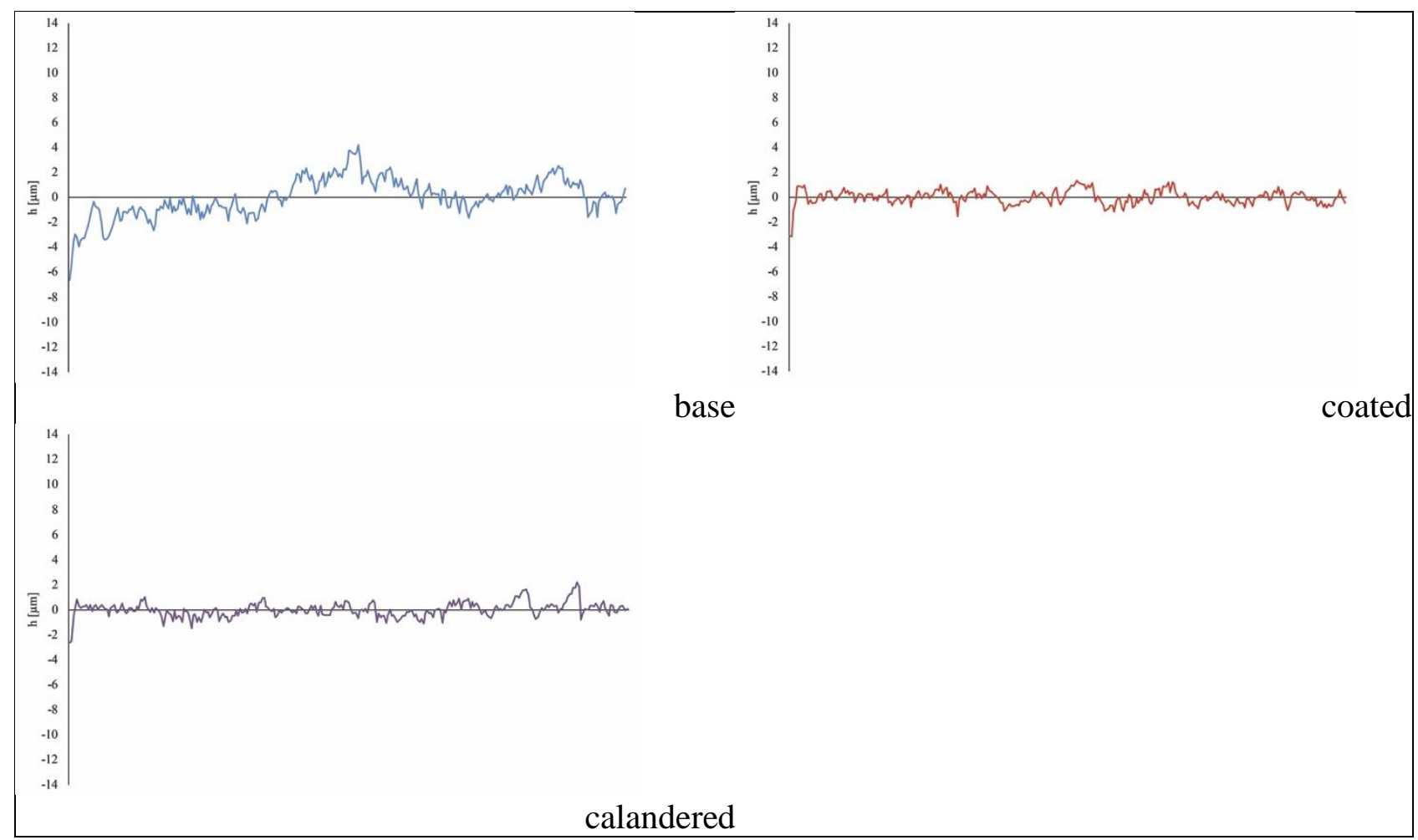

Fig. 7. Profile of surface roughness - Instron.

Therefore, one mayor conclusion can be extracted, i.e. the novel model, Instron, is, as presented from the results, as good as the 3D laser scanning microscope technique, but with one great difference. It costs less to build and run and it is more a modular type, where the stylus and burden can be adjusted to the nature of the measuring surface (paper, metal, wood, etc.).

\section{Conclusion}

The introduced novel contact method for measuring the surface topography, i.e. Instron, has confirm that with a small upgrade of existing dynamometer (wheel carrier and software), the developed technique can be used as an additional tool when an exact measurement apparatus, e.g. profilometer or even one of the more expensive, noncontact method, e.g. 3D laser scanning microscope or another equivalent laboratory equipment, are not available. The presented contact method has greater similarity with the non-contact method as it has with the standard profilometer. 
Even though the presented results are optimistic, they need to be confirmed on the variety of papers or even different kind of surfaces, e.g. metal, wood, rubber, etc. Therefore, the presented results of a novel contact method, Instron, confirm the accuracy of physical interpretation of surface nature, even better, it can be used to measure surface topography with the precision of a laser profilometry.

\section{References}

Aguilar, J. R., Arenas, J. P. \& Salinas R. (2009). Friction noise technique for the measurement of surface roughness of paper. Applied Acoustics, Vol. 70, No. 9, 12351240 .

Al-Kindi, G., Baul, R. \& Gill, K. (1992). An application of machine vision in the automated inspection of engineering surfaces. International Journal of Production Research, Vol. 30, No. 2, 241-253.

Alam, A., Thim, J., O'Nils, M., Manuilskiy, A., Lindgren, J. \& Lidén, J. (2012). Online surface characterization of paper and paperboards in a wide-range of the spatial wavelength spectrum. Applied Surface Science, Vol. 258, No. 20, 7928-7935.

Alarousu, E., Krehut, L., Prykäri, T. \& Myllylä, R. (2005). Study on the use of optical coherence tomography in measurements of paper properties. Measurement Science and Technology, Vol. 16, No. 5, 1131-1137.

Alava, M. \& Niskanen, K. (2006). The physics of paper. Reports on Progress in Physics, Vol. 69, No. 3, 669-723.

Asakura, T. (1978). Speckle metrology, Chapter 3: Surface roughness measurement. Editor R. K. Erf. Academic Press, Inc., p. 11-13.

Asl-Kindi, G. \& Shirinzadeh, B. (2009). Feasibility assessment of vision-based surface roughness parameters acquisition for different types of machined specimens. Image and Vision Computing, Vol. 27, No. 4, 444-458.

Baghello, L. \& Eklund, D. (1997). Some mechanisms that govern fibre flocculation. Nordic Pulp and Paper Research Journal, Vol. 12, No. 2, 119-123.

Bennett, J. M. (1992). Recent developments in surface roughness characterization. Measurement Science and Technology, Vol. 3, No. 12, 1119-1127.

Brodeur, P. H., Hall, M. S. \& Esworthy, C. (1993). Sound dispersion and attenuation in the thickness direction of paper materials. Journal of the Acoustical Society of America, Vol. 94, No. 4, 2215-2225.

Despond, S., Espuche, E., Cartier, N. \& Domard, A. (2005). Barrier properties of paper-chitosan and paper-chitosan-carnauba wax films. Journal of Applied Polymer Science, Vol. 98, No. 2, 704-710.

Dury Bruna, C., Juryb, V., Guillardb, V., Desobryc, S., Voilleya, A. \& Chalier P. (2006). Water barrier properties of treated-papers and application to sponge cake storage. Food Researc International, Vol. 39, No. 9, 1002-1011. 
Hiziroglu, S. (1996). Surface roughness analysis of wood composites: a stylus method. Forest Product Journal, Vol. 46, No. 7-8, 67-72.

ISO 4287: Geometrical products specification (GPS) - Surface texture: Profile method - Terms, definitions and surface texture parameters; 1997, $25 \mathrm{p}$.

Johansson, A., Fellers, C., Gunderson, D. \& Haugen, U. (1998). Paper frictioninfluence of measurement conditions. Tappi Journal, Vol. 81, No. 5, 175-183.

Juuti, M., Prykäri, T., Alarousu, E., Koivula, H., Myllys, M., Lähteelä, A., Toivakka, M., Timonen, J., Myllylä, R. \& Peiponen, R. M. (2007). Detection of local specular gloss and surface roughness from black prints. Colloids and Surfaces A: Physicochemical and Engineering Aspects, Vol. 299, No. 1-3, 101-108.

Kettle, J., Lmminmäki, T. \& Gane, P. (2010). A review of modified surfaces for high speed inkjet coating. Surface and Coating Technology, Vol. 204, No. 12-13, 21032109.

Kiran, M. B., Ramamoorthy, B. \& Radhakrishnan, V. (1998). Evaluation of surface roughness by vision system. International Journal of Machine Tools and Manufacture, Vol. 38, No. 5-6, 685-690.

Koran, Z., Silvy, J. \& Prud'homme, R. E. (1986). Network structure and fibre orientation in paper. Tappi Journal, Vol. 69, No. 5, 126-128.

Kortschot, M. T. (1997). The role of the fiber in the structural hierarchy of paper. The Fundamentals of Papermaking Materials, The Eleventh Fundamental Research Symposium, 21-26 September 1997, Cambridge: Pira International, 351-394.

Maculotti, G., Feng, X., Galetto, M. \& Leach R. (2018). Noise valuation of a point autofocus surface topography measuring instrument. Measurement Science and Technology, Vol. 29, No. 6, 8 pp.

Mitsui, K. (1986). In process sensors for surface roughness and their applications. Precision Engineering, Vol. 8, No. 4, 212-220.

Ohtsubo, J., Fuji, H. \& Asakura, T. (1975). Surface roughness measurement by using speckle pattern. Japanese Journal of Applied Physics, Vol. 14, No. 1, 293-298.

Ostman, B. A. L. (1983). Surface roughness of wood-based panels after aging. Forests Products Journal, Vol. 33, No. 7-8, 35-42.

Persson, U. (1999). A fibre-optic surface-roughness sensor. Journal of Materials Processing Technology, Vol. 95, No. 1-3, 107-111.

Persson, U. (2006). Surface roughness measurement on machined surfaces using angular speckle correlation. Journal of Material Processing Technology, Vol. 180, No. 1-3, 233-238.

Peter, C. C. \& Cumming, J. D. (1970). Measuring wood surface smoothness: a review. Forests Products Journal, Vol. 20, No. 12, 40-43.

Reis, M. S. \& Saraiva, P. M. (2006). Multiscale analysis and monitoring of paper surface. 16th European Symposium on Computer Aided Process Engineering and 9th International Symposium on Process Systems Engineering, Computer-Aided Chemical 
Engineering, Vol. 21B, Marquardt, W. \& Pantelides C. (Ed.), pp. 1173-1178, ISSN 1570-7946.

Samyn, P., Van Erps, J., Thienpont, H. \& Schoukens, G. (2011). Paper coatings with multi-scale roughness evaluated at different sampling sizes. Applied Surface Science, Vol. 257, No. 13, 5613-5625.

Stor-Pellinen, J. \& Luukkala, M. (1995). Paper roughness measurement using airborne ultrasound. Sensors and Actuators A: Physical, Vol. 49, No. 1-2, 37-40.

Tammineni, L. \& Reddy Yedula, H. P. (2014). Investigation of influence of milling parameters on surface roughness and flatness. International Journal of Advances in Engineering and Technology, Vol. 6, No. 6, 2416-2426.

Tasan, Y., De Rooij, M. \& Schipper, D. (2005). Measurements of wear on asperity level using image-processing technique. Wear, Vol. 258, No. 1-4, 83-91.

Wyant, J. C, Kwon, O. \& Hayslett, C. R. (1980). Rough surface interferometry at 10,6 $\mu \mathrm{m}$. Applied Optics, Vol. 19, No. 11, 1862-1869.

Zhou, Q., Ren, P. \& Tan, Y. L. (2012). Soft measurement of paper smoothness based on time-frequency analysis of paper quantization noise. Measurement, Vol. 45, No. 3, 493-499. 